\title{
Neurostimulation Treatment in Chronic Cluster Headache-a Narrative Review
}

\author{
Stefan Evers ${ }^{1,2} \cdot$ Oliver Summ ${ }^{3,4}$ \\ Accepted: 27 September 2021 / Published online: 11 December 2021 \\ (c) The Author(s) 2021
}

\begin{abstract}
Purpose of Review In this narrative review, the current literature on neurostimulation methods in the treatment of chronic cluster headache is evaluated. These neurostimulation methods include deep brain stimulation, vagus nerve stimulation, greater occipital nerve stimulation, sphenopalatine ganglion stimulation, transcranial magnetic stimulation, transcranial direct current stimulation, supraorbital nerve stimulation, and cervical spinal cord stimulation.

Recent Findings Altogether, only nVNS and SPG stimulation are supported by at least one positive sham-controlled clinical trial for preventive and acute attack (only SPG stimulation) treatment. Other clinical trials either did not control at all or controlled by differences in the stimulation technique itself but not by a sham-control. Case series report higher responder rates. Summary The evidence for these neurostimulation methods in the treatment of chronic cluster headache is poor and in part contradictive. However, except deep brain stimulation, tolerability and safety of these methods are good so that in refractory situations application might be justified in individual cases.
\end{abstract}

Keywords Cluster headache - Deep brain stimulation - Vagus nerve stimulation · Sphenopalatine ganglion stimulation · Greater occipital nerve stimulation

\section{Introduction}

Neurostimulation has become a major focus in the treatment research on idiopathic headache disorders. In particular, migraine and cluster headache have been studied whether these disorders respond to different types of neurostimulation (with respect to both stimulation technique and anatomical region). In this narrative review, we aim to give a brief clinical summary of the published evidence for different

This article is part of the Topical Collection on Chronic Daily Headache

Stefan Evers

everss@uni-muenster.de

1 Faculty of Medicine, University of Münster, Münster, Germany

2 Lindenbrunn Hospital, Coppenbrügge, Germany

3 Department of Neurology and Research Center of Neurosensory Science, Carl Von Ossietzky University, Oldenburg, Germany

4 Department of Neurological Intensive Care and Rehabilitation, Evangelisches Krankenhaus Oldenburg, Oldenburg, Germany stimulation types in chronic cluster headache (CCH). The approach of neurostimulation in cluster headache is however not really new. Already in 1950, an experiment was published showing that stimulation of nerve fibres of the sphenopalatine ganglion in provoked cluster headache attacks was efficacious [1].

When reviewing neurostimulation in $\mathrm{CCH}$, the following aspects have to be considered:

- Stimulation technique

- Acute or preventive treatment

- Site of stimulation

We decided to structure our review according to the site of stimulation since this is in concordance with the major clinical trials.

\section{Deep Brain Stimulation}

Deep brain stimulation (DBS) of the ipsilateral posterior hypothalamus was the first specific stimulation technique published on the treatment of refractory $\mathrm{CCH}$ [2]. This technique was developed following the neuroimaging 
finding that activation of the posterior hypothalamus plays a major role in cluster headache attacks [3]. Since the first published positive case report [2], several case series with number of patients between 4 and 21 have been published until now, reporting an efficacy in $\mathrm{CCH}$ prevention with more than $50 \%$ responders [4•, 5-13]. All reports differ slightly with respect to the exact anatomical localisation (major alternative sites are the ventral tegmental area; midbrain ventral and retrorubral tegmentum; endoventricular site of the third ventricle wall; dorsal longitudinal and mamillotegmental fasciculi) and with respect to the exact parameters of the stimulation.

The effects of DBS seem to remain stable in most patients over a long time. One observational study followed patients with DBS $(n=7)$ and patients with greater occipital nerve $(\mathrm{GON})$ stimulation $(n=17)$ over 48 months [13]. All the patients from the DBS group were considered responders at final follow-up, with more than $85 \%$ being satisfied with the treatment; approximately $29 \%$ of initial responders to GON stimulation became resistant at the final follow-up. A meta-analysis of published cases $(n=40)$ found a significant $77 \%$ mean reduction in headache attack frequency over a mean follow-up of 44 months, with an overall response rate of 75\% [14]; another case series with an observation period over 8.7 years showed also consistent efficacy of DBS in $\mathrm{CCH}$ in $70 \%$ without side effects (15Leone 2013). Positive outcome was not associated with demographic covariates, negative outcome was associated with bilateral cluster headache. The findings confirming long-term effectiveness of DBS for $\mathrm{CCH}$ suggest that the neuroanatomical substrate of deep brain stimulation-induced headache relief is probably not restricted to the posterior hypothalamic area but encompasses a more widespread area in the midbrain.

Acute $\mathrm{CCH}$ attack treatment by DBS was also studied, but only $23 \%$ of all attacks in a larger case series were improved by direct DBS stimulation; therefore, DBS cannot be regarded as effective in the treatment of attacks [16].

The enthusiasm for this technique decreased when an intracerebral haemorrhage due to the implantation procedure was reported [5]. Another setback for the development of this technique was the first randomised, prospective, crossover, double-blind study assessing the efficacy and safety of ipsilateral hypothalamic DBS in 11 patients with severe refractory $\mathrm{CCH}[17 \bullet]$. During the randomised phase, no significant change in primary and secondary outcome measures was observed between active and sham stimulation. There were three serious adverse events, including subcutaneous infection, transient loss of consciousness and micturition syncopes. It has also been shown that DBS in $\mathrm{CCH}$ does not result in a change of cognition [18].
DBS has also been applied in other trigemino-autonomic cephalalgias such as short-lasting unilateral neuralgiform headache attacks with conjunctival injection and tearing (SUNCT; $n=2$ ) and for chronic paroxysmal hemicranias $(n=1)$ [19]. In these cases, the contralateral hypothalamus was (also) stimulated.

\section{Vagus Nerve Stimulation}

Vagus nerve stimulation has been studied as non-invasive (transdermal) stimulation at the neck (along the carotid artery) for migraine and cluster headache; the common abbreviation for this technique is nVNS. It can be used as acute attack treatment or as preventive treatment by regular daily stimulation. A small observational study with 18 patients including 11 with $\mathrm{CCH}$ showed an improvement by $50 \%$ for both acute and preventive treatment [20].

In a prospective, open-label, randomised study in $\mathrm{CCH}$ patients, add-on prophylactic nVNS $(n=48)$ was compared with standard of care $(\mathrm{SoC})$ alone $(n=49)$ [21 $\bullet$. During the randomised phase, individuals in the intent-to-treat population treated with SoC plus nVNS had a significantly greater reduction in the number of attacks per week than control patients $(-5.9$ versus -2.1$)$. The rate of responders $(>50 \%$ reduction) was also higher in SoC plus nVNS (40\%) than in control patients $(8.3 \%)$. No serious treatment-related adverse events occurred.

A retrospective observational study in the UK showed a mean $\mathrm{CCH}$ attack frequency from $26.6+/-17.1$ attacks per week before initiation of nVNS therapy to $9.5+/-11.0$ attacks per week $(p<0.01)$ afterwards. Also, attack duration, attack severity, and use of abortive treatments decreased [22].

The efficacy of nVNS on acute attacks in cluster headache has been studied in two randomised sham-controlled studies [23, 24•]. Interestingly, both studies showed that acute attack treatment by nVNS has significant efficacy in attack abortion in episodic cluster headache attacks but not in $\mathrm{CCH}$ attacks. Interestingly, however, it has also been shown that nVNS is cost-effective in $\mathrm{CCH}$, at least for acute attack treatment [25].

\section{Greater Occipital Nerve Stimulation}

Greater occipital nerve (GON) stimulation with implanted electrodes in $\mathrm{CCH}$ has first been reported in 2007 with a case series of 8 patients responding between 25 and $95 \%$ attack frequency reduction [26]; the same group confirmed this result in a larger case series of 18 patients with medically intractable cluster headache [27]. Other case series reported a substantial effect of GON stimulation in 7 out 
of 8 patients [28] and in 9 out of 10 patients [29]. A mean attack frequency and intensity decrease by $68 \%$ and $49 \%$, respectively, was observed in 13 patients [30], local infection occurred in one patient, leading to hardware removal. Another large case series on GON stimulation in $\mathrm{CCH}$ (51 patients) reported at least 50\% improvement of attack frequency in 53\% of patients [31]. In a long-term observational study with a median follow-up of 6.1 years, $67 \%$ of the patients were responders $(\geq 50 \%$ reduction in headache attacks per day) and $40 \%$ responders showed a stable condition characterised by only sporadic attacks [32].

A recent and large $(n=105)$ observational study showed an attack frequency reduction by $>50 \%$ in $69 \%$ of the patients [33•]. Mean weekly attack frequency decreased from 22.5 at baseline to 9.9 after GON stimulation. Preventive and abortive medications were significantly decreased. When comparing baseline and 1-year and last follow-up outcomes, efficacy was sustained over time. During the follow-up, 67 patients experienced at least one complication, 29 requiring an additional surgery: infection $(6 \%)$, lead migration $(12 \%)$ or fracture $(4.5 \%)$, hardware dysfunction $(8.2 \%)$, and local pain $(20 \%)$.

Most recently, a randomised, double-blind, electrical dose-controlled clinical trial has been performed showing an efficacy of both $100 \%$ and $30 \%$ GON stimulation intensity in 130 patients with $\mathrm{CCH}$ with no significant difference between the two stimulation intensities [34•]. A median decrease of $\mathrm{CCH}$ attacks by 4.1 per week in the $100 \%$ stimulation group and by 6.5 per week for the $30 \%$ stimulation group was observed. The most common adverse events were local pain, impaired wound healing, neck stiffness, and hardware damage. This study was interpreted as positive although there was no sham control.

GON stimulation for the treatment of refractory $\mathrm{CCH}$ and chronic migraine has been regarded as a cost-intensive treatment option with a significant complication rate [35]. However, occipital nerve stimulation for refractory $\mathrm{CCH}$ is the only available invasive approach with a Conformité Européenne (CE) mark.

An alternative technique to GON invasive stimulation is subcutaneous GON stimulation which has however only been reported in small case series by the same group [36, 37]. Another alternative technique is bilateral burst stimulation of the GON which produces less paresthesia. The efficacy of this technique in $\mathrm{CCH}$ has only been shown in a small case series of $n=5$ [38].

\section{Sphenopalatine Ganglion Stimulation}

A further target for electrical stimulation is the sphenopalatine ganglion (SPG). Clinically, the involvement of the SPG in the pathophysiology of trigeminoautonomic headache is evident by symptoms as lacrimation, nasal congestion or rhinorrhea. These symptoms are driven by nerval activation of parasympathic fibres that synapse in the SPG. Anatomically the SPG is located in the pterygopalatine fossa and comprises the parasympathic synapse and parasympathetic cell bodies as well as sensory axons and sympathetic fibres which are post-synaptic.

Research in animal studies as well as in human studies gave further insights to the pathophysiological circuits of activity in regions as the hypothalamus, brainstem and activation of efferent parasympathic fibres with effect on afferent trigeminal fibres as it can be observed in the trigeminal autonomic reflex arc [3, 39-41]. Interestingly, pharmacological treatments with an effect on trigeminoautonomic cephalalgias were shown to substantially modulate autonomic outflow [41] in an animal model of trigeminal cephalalgias, underlining SPG as a target for treatment of trigeminoautonomic headaches. Applied in humans, low frequency stimulation of the SPG is able to provoke autonomic symptoms attributed to an activation of the parasympathic outflow from the SPG through the applied low frequency stimulation, whilst high frequency stimulation is attributed to a blockage of the parasympathic outflow [42, 43]. Contrary to the initial trial [42] cluster like headaches were not demonstrated being triggered by low-frequency stimulation of the SPG in a double-blind randomised sham-controlled crossover study [43].

Favourable results of SPG stimulation, applied as pulsed treatment either during attacks or repeatedly on daily basis, were reported in an open label follow-up study of the Pathway $\mathrm{CH}-1$ study in which 33 patients with $\mathrm{CCH}$ were followed up for 24 months [44]. In this study, it has been demonstrated that in $30 \%$ of these patients a minimum of one period of attack remission was observed beginning after a treatment period of about 3.5 months, also the HIT-6 score as a marker for the headache disability improved by an average of 12.5 points. In another report of this group, $45 \%$ of the patients were described as being acute responders at 24 months and $33 \%$ patients responded in terms of a frequency reduction, drawn together the total response observed was $61 \%$ [45]. Summarised in the most recent report of this group, $88 \mathrm{CCH}$ patients with SPG stimulation of which 78 stayed implanted were included and followed up for 12 months, all these patients were responders by measures of HIT-6 and $67 \%$ responded in the SF-36 [46]. A frequency reduction was seen in $55 \%, 32 \%$ were acute responders, and an overall response was documented in $68 \%$. Seventy-four percent of the $\mathrm{CCH}$ patients were even able to stop, reduce, or remain of all preventive medication. In a smaller case series, 11 out of 18 attacks in patients with intractable $\mathrm{CCH}$ were completely aborted by SPG stimulation [47].

The observation of 36 patients in a SPG stimulated group versus 40 sham-stimulated patients in a US-based 
randomised, sham-controlled, parallel group, double-blind, safety and efficacy study, demonstrated an even higher rate

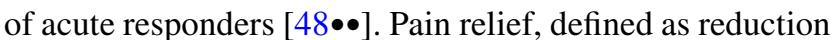
from a minimum of moderate pain to none or mild pain, experienced at 15 min poststimulation was documented in $62 \%$, whilst the response in terms of median frequency reduction was at least $75 \%$. Adverse events most commonly seen after implantation of SPG stimulator and concomitant stimulation were sensory disturbances (with stimulation),

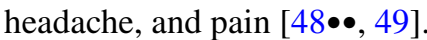

The approach of pulsed radiofrequency of the SPG in patients with $\mathrm{CCH}$ is another invasive option for the treatment. Case reports and series report on different outcomes, e.g. it led to unsuccessful treatment of the pain as well as the autonomic function in three reported patients, whereas they were reported being successfully treated by thermocoagulation of the SPG, though the follow-up ended after 11 month [50]. However, in a prospective analysis of the treatment with radiofrequency ablation or pulsed radiofrequency, 37 patients with $\mathrm{CCH}$ were followed up by a mean of 68 months, only $30 \%$ of the patients were reported not having improved but five of the patients even demonstrated a total relief of headache and autonomic symptoms [51]. It will have to be demonstrated in further comparisons which technique will be more successful in the treatment of pain and safer for the patient as there has been shown a low complication rate reported [51] in comparison to stimulation of the SPG.

\section{Transcranial Magnetic Stimulation}

Transcranial magnetic stimulation (TMS) offers an interesting opportunity as it is a well-established technique for other indications that can be applied safely without direct stimulation via implants and therefore potential adverse events as infection or migration of implant as well as the necessity of exchange of an energy source are avoided. TMS is able to generate a small electric current on the cortex area stimulated through electromagnetic induction that is highly specific to a defined area in dependence to the parameters, i.e. single-pulse TMS, high- or low-frequency repetitive TMS, and configuration of the stimulation coil used. TMS was demonstrated being able to inhibit the propagation of cortical spreading depression (CSD) which is accepted as the pathophysiological correlate of migraine aura thus its role in migraine without aura still is under debate [52].

With a focus on treatment of headache symptoms, positive studies on the application of TMS are evident for the blockade of CSD in animal studies [52]. Single-pulse TMS applied at the occiput has demonstrated effectiveness in acute treatment of migraine pain in patients suffering from migraine with aura [53], paralleled by a migraine preventive effect [54] that is also observed in repetitive TMS over the M1 area [55]. Taken together, the data from the available studies led to the rating as moderate recommendable for migraine pain prevention, and recommendable for migraine prevention in terms of reduction of headache days, by the International and the North American Neuromodulation Society (INS and NANDS) [56].

In $\mathrm{CCH}$, however, no recommendation can be made for TMS treatment, as there is a lack of randomised controlled trials, though an open-label observational study including 19 patients suffering from $\mathrm{CCH}$ reported a beneficial outcome of repetitive $(10 \mathrm{~Hz})$ TMS over the M1 area. Paroxysmal pain and number of attacks were reduced when comparing baseline with 15 days poststimulation measures [57]. Although in this report permanent pain was reported in 8 of the cluster headache patients, it remains unclear if those fulfilled the definition of $\mathrm{CCH}$; therefore, no clear data are available on the use of TMS in $\mathrm{CCH}$.

\section{Transcranial Direct Current Stimulation}

Transcranial direct current stimulation (tDCS) (anode at Fz, cathode over $\mathrm{C7}$ ) for refractory $\mathrm{CCH}$ patients has only been studied in a proof-of-concept study [58] with a mean attack frequency reduction by $35 \%$. The method was well tolerated. There are no more data available on this method in $\mathrm{CCH}$ at the moment.

\section{Supraorbital Nerve Stimulation}

The stimulation of the supraorbital nerve in $\mathrm{CCH}$ patients has only been described in case reports. These described positive responses in the patients $[59,60]$; no more data on this technique as a single treatment is available.

\section{Cervical Spinal Cord Stimulation}

One case series described the efficacy of high spinal cord stimulation in refractory $\mathrm{CCH}$ patients [61]. All seven patients showed significant treatment effects with immediate improvement after electrode implantation. This was confirmed by a single case report of $\mathrm{CCH}$ [62].

\section{Conclusion}

This narrative review shows that there is a variety of techniques which has been applied to patients with $\mathrm{CCH}$. Most of these techniques were detected empirically; however, DBS and SPG stimulation follow our current knowledge on the pathophysiology of cluster headache. In summary, nearly all techniques are safe and well tolerated. Only DBS electrodes should be implanted with very high caution since fatal outcome of the operation has been reported. 
Table 1 Stimulation techniques and their efficacy in chronic cluster headache according to published evidence

\begin{tabular}{|c|c|c|}
\hline Techniques & $\mathrm{RCT}$ & Open trials \\
\hline \multicolumn{3}{|l|}{ Preventive treatment } \\
\hline DBS & One trial negative & $\begin{array}{l}\text { Several case series posi- } \\
\text { tive; consistent efficacy } \\
\text { over years }\end{array}$ \\
\hline nVNS & One trial positive & Some case series positive \\
\hline GON stimulation & $\begin{array}{l}\text { One trial positive } \\
\text { without sham }\end{array}$ & $\begin{array}{l}\text { Several case series posi- } \\
\text { tive }\end{array}$ \\
\hline SPG stimulation & One trial positive & Larger case series positive \\
\hline SPG radiofrequency & None & $\begin{array}{l}\text { Two small case series } \\
\text { positive }\end{array}$ \\
\hline TMS & None & $\begin{array}{l}\text { One small case series } \\
\text { positive }\end{array}$ \\
\hline \multicolumn{3}{|l|}{ Acute treatment } \\
\hline DBS & None & $\begin{array}{l}\text { One small case series } \\
\text { negative }\end{array}$ \\
\hline nVNS & Two trials negative & Only reports \\
\hline SPG stimulation & Two trials positive & Small case series positive \\
\hline
\end{tabular}

The highest rate of technical problems after implantation has been reported for GON stimulation.

The efficacy of all stimulation procedures has been reported as quite high, at least in the open case series and observational studies. The randomised trials, if any, showed poorer results. We summarised the results for the different stimulation techniques and the preventive and acute treatment in a subjective way (Table 1). However, this overview shows that only nVNS and SPG stimulation are supported by at least one positive sham-controlled clinical trial. Other clinical trials either did not control at all or controlled by differences in the stimulation technique itself but not by a sham-control.

The real efficacy of the stimulation techniques remains also unknown since only refractory patients were treated (and included in trials). It might be that patients responding to oral drugs also respond to stimulation techniques. It remains to be debated whether neurostimulation should be restricted only to refractory $\mathrm{CCH}$ patients.

One option for future applications might be the combination of different stimulation techniques, as it has been tried in migraine. Only one case report combining DBS and nVNS [63] and one case report combining GON stimulation with supraorbital and infraorbital nerve stimulation [64] are available. Another approach is the sequential application of the different techniques described above. This has been tested in an observational study on 44 patients with $\mathrm{CCH}$ who received first SPG stimulation, then (if SPG stimulation was ineffective) GON stimulation and then (if GON stimulation was ineffective) DBS stimulation resulting in a total responder rate of $93 \%$ [65].
In conclusion, there is a lot of open data but only very poor clinical evidence for the efficacy of neurostimulation techniques in the treatment of $\mathrm{CCH}$. Since this condition is extremely disabling and often refractory to drugs, it is justified to try such stimulation techniques as last option. However, one should follow clinical evidence and safety concerns as reported in this review.

Funding Open Access funding enabled and organized by Projekt DEAL.

\section{Declarations}

Conflict of Interest Stefan Evers has received honoraria for consulting and speaking in the past 3 years from Allergan, Lilly, Lundbeck, Novartis, and Teva. Oliver Summ has received support for training from Allergan.

Human and Animal Rights and Informed Consent This article does not contain any studies with human or animal subjects performed by any of the authors.

Open Access This article is licensed under a Creative Commons Attribution 4.0 International License, which permits use, sharing, adaptation, distribution and reproduction in any medium or format, as long as you give appropriate credit to the original author(s) and the source, provide a link to the Creative Commons licence, and indicate if changes were made. The images or other third party material in this article are included in the article's Creative Commons licence, unless indicated otherwise in a credit line to the material. If material is not included in the article's Creative Commons licence and your intended use is not permitted by statutory regulation or exceeds the permitted use, you will need to obtain permission directly from the copyright holder. To view a copy of this licence, visit http://creativecommons.org/licenses/by/4.0/.

\section{References}

Papers of particular interest, published recently, have been highlighted as:

- Of importance

$\bullet$ Of major importance

1. Martinetti R, Pini E. La stimolazione dei rami nervosi provenienti dal ganglio sfeno-palatino è capace di interrompere la cefalea istaminica provocata. Sperimentale. 1950;100:160-7.

2. Leone M, Franzini A, Bussone G. Stereotactic stimulation of posterior hypothalamic gray matter in a patient with intractable cluster headache. N Engl J Med. 2001;345:1428-9.

3. May A, Bahra A, Buchel C, Frackowiak RS, Goadsby PJ. Hypothalamic activation in cluster headache attacks. Lancet. 1998;352:275-8.

4. Franzini A, Ferroli P, Leone M, Broggi G. Stimulation of the posterior hypothalamus for treatment of chronic intractable cluster headaches: first reported series. Neurosurgery. 2003;52:10951099. First case series on deep brain stimulation.

5. Schoenen J, Di Clemente L, Vandenheede M, Fumal A, De Pasqua V, Mouchamps M, Remacle JM, de Noordhout AM. Hypothalamic 
stimulation in chronic cluster headache: a pilot study of efficacy and mode of action. Brain. 2005;128:940-7.

6. Starr PA, Barbaro NM, Raskin NH, Ostrem JL. Chronic stimulation of the posterior hypothalamic region for cluster headache: technique and 1-year results in four patients. J Neurosurg. 2007;106:999-1005.

7. Bartsch T, Pinsker MO, Rasche D, Kinfe T, Hertel F, Diener HC, Tronnier V, Mehdorn HM, Volkmann J, Deuschl G, Krauss JK. Hypothalamic deep brain stimulation for cluster headache: experience from a new multicase series. Cephalalgia. 2008;28:285-95.

8. Seijo F, Saiz A, Lozano B, Santamarta E, Alvarez-Vega M, Seijo E, Fernández de León R, Fernández-González F, Pascual J. Neuromodulation of the posterolateral hypothalamus for the treatment of chronic refractory cluster headache: Experience in five patients with a modified anatomical target. Cephalalgia. 2011;31:1634-1641.

9. Akram H, Miller S, Lagrata S, Hyam J, Jahanshahi M, Hariz M, Matharu M, Zrinzo L. Ventral tegmental area deep brain stimulation for refractory chronic cluster headache. Neurology. 2016;86:1676-82.

10. Chabardès S, Carron R, Seigneuret E, Torres N, Goetz L, Krainik A, Piallat B, Pham P, David O, Giraud P, Benabid AL. Endoventricular deep brain stimulation of the third ventricle: proof of concept and application to cluster headache. Neurosurgery. 2016;79:806-15.

11. Seijo-Fernandez F, Saiz A, Santamarta E, Nader L, Alvarez-Vega MA, Lozano B, Seijo E, Barcia JA. Long-term results of deep brain stimulation of the mamillotegmental fasciculus in chronic cluster headache. Stereotact Funct Neurosurg. 2018;96:215-22.

12. Nowacki A, Moir L, Owen SL, Fitzgerald JJ, Green AL, Aziz TZ. Deep brain stimulation of chronic cluster headaches: Posterior hypothalamus, ventral tegmentum and beyond. Cephalalgia. 2019;39:1111-20.

13. Aibar-Durán JÁ, Álvarez Holzapfel MJ, Rodríguez Rodríguez R, Belvis Nieto R, Roig Arnall C, Molet TJ. Occipital nerve stimulation and deep brain stimulation for refractory cluster headache: a prospective analysis of efficacy over time. J Neurosurg. 2020;17:1-8.

14. Nowacki A, Schober M, Nader L, Saryyeva A, Nguyen TK, Green AL, Pollo C, Krauss JK, Fontaine D, Aziz TZ. Deep brain stimulation for chronic cluster headache: meta-analysis of individual patient data. Ann Neurol. 2020;88:956-69.

15. Leone M, Franzini A, Cecchini AP, Bussone G. Success, failure, and putative mechanisms in hypothalamic stimulation for drugresistant chronic cluster headache. Pain. 2013;154:89-94.

16. Leone M, Franzini A, Broggi G, Mea E, Cecchini AP, Bussone G. Acute hypothalamic stimulation and ongoing cluster headache attacks. Neurology. 2006;67:1844-5.

17. Fontaine D, Lazorthes Y, Mertens P, Blond S, Géraud G, Fabre N, Navez M, Lucas C, Dubois F, Gonfrier S, Paquis P, LantériMinet M. Safety and efficacy of deep brain stimulation in refractory cluster headache: a randomized placebo-controlled doubleblind trial followed by a 1 -year open extension. J Headache Pain. 2010;11:23-31. Only randomized sham-controlled trial for deep brain stimulation; reporting a negative result.

18. Cappon D, Ryterska A, Lagrata S, Miller S, Akram H, Hyam J, Zrinzo L, Matharu M, Jahanshahi M. Ventral tegmental area deep brain stimulation for chronic cluster headache: Effects on cognition, mood, pain report behaviour and quality of life. Cephalalgia. 2019;39:1099-110.

19. Franzini A, Messina G, Cordella R, Marras C, Broggi G. Deep brain stimulation of the posteromedial hypothalamus: indications, long-term results, and neurophysiological considerations. Neurosurg Focus. 2010;29:E13.

20. Nesbitt AD, Marin JC, Tompkins E, Ruttledge MH, Goadsby PJ. Initial use of a novel noninvasive vagus nerve stimulator for cluster headache treatment. Neurology. 2015;84:1249-53.
21.• Gaul C, Diener HC, Silver N, Magis D, Reuter U, Andersson A, Liebler EJ, Straube A; PREVA Study Group. Non-invasive vagus nerve stimulation for PREVention and Acute treatment of chronic cluster headache (PREVA): A randomised controlled study. Cephalalgia. 2016;36:534-546. Controlled trial on vagus nerve stimulation reporting on both acute and prophylactic treatment.

22. Marin J, Giffin N, Consiglio E, McClure C, Liebler E, Davies B. Non-invasive vagus nerve stimulation for treatment of cluster headache: early UK clinical experience. J Headache Pain. 2018;19:114.

23. Silberstein SD, Mechtler LL, Kudrow DB, Calhoun AH, McClure C, Saper JR, Liebler EJ, Rubenstein Engel E, Tepper SJ; ACT1 Study Group. Non-invasive vagus nerve stimulation for the ACute Treatment of cluster headache: findings from the randomized, double-blind, sham-controlled ACT1 study. Headache. 2016;56:1317-1332.

24. Goadsby PJ, de Coo IF, Silver N, Tyagi A, Ahmed F, Gaul C, Jensen RH, Diener HC, Solbach K, Straube A, Liebler E, Marin JC, Ferrari MD; ACT2 Study Group. Non-invasive vagus nerve stimulation for the acute treatment of episodic and chronic cluster headache: a randomized, double-blind, sham-controlled ACT2 study. Cephalalgia. 2018;38:959-969. Only sham-controlled trial on vagus nerve stimulation.

25. Morris J, Straube A, Diener HC, Ahmed F, Silver N, Walker S, Liebler E, Gaul C. Cost-effectiveness analysis of non-invasive vagus nerve stimulation for the treatment of chronic cluster headache. J Headache Pain. 2016;17:43.

26. Burns B, Watkins L, Goadsby PJ. Treatment of medically intractable cluster headache by occipital nerve stimulation: long-term follow-up of eight patients. Lancet. 2007;369:1099-106.

27. Burns B, Watkins L, Goadsby PJ. Treatment of intractable chronic cluster headache by occipital nerve stimulation in 14 patients. Neurology. 2009;72:341-5.

28. Magis D, Allena M, Bolla M, De Pasqua V, Remacle JM, Schoenen J. Occipital nerve stimulation for drug-resistant chronic cluster headache: a prospective pilot study. Lancet Neurol. 2007;6:314-21.

29. Mueller O, Diener HC, Dammann P, Rabe K, Hagel V, Sure U, Gaul C. Occipital nerve stimulation for intractable chronic cluster headache or migraine: a critical analysis of direct treatment costs and complications. Cephalalgia. 2013;33:1283-91.

30. Fontaine D, Christophe Sol J, Raoul S, Fabre N, Geraud G, Magne C, Sakarovitch C, Lanteri-Minet M. Treatment of refractory chronic cluster headache by chronic occipital nerve stimulation. Cephalalgia. 2011;31:1101-5.

31. Miller S, Watkins L, Matharu M. Treatment of intractable chronic cluster headache by occipital nerve stimulation: a cohort of 51 patients. Eur J Neurol. 2017;24:381-90.

32. Leone M, Proietti Cecchini A, Messina G, Franzini A. Longterm occipital nerve stimulation for drug-resistant chronic cluster headache. Cephalalgia. 2017;37:756-63.

33. Leplus A, Fontaine D, Donnet A, Regis J, Lucas C, Buisset N, Blond S, Raoul S, Guegan-Massardier E, Derrey S, Jarraya B, Dang-Vu B, Bourdain F, Valade D, Roos C, Creach C, Chabardes S, Giraud P, Voirin J, Bloch J, Colnat-Coulbois S, Caire F, Rigoard P, Tran L, Cruzel C, Lantéri-Minet M; French ONS registry group. Long-term efficacy of occipital nerve stimulation for medically intractable cluster headache. Neurosurgery. 2021;88:375383. Large observational study reporting good efficacy of greater occipital nerve stimulation but also adverse events

34. Wilbrink LA, de Coo IF, Doesborg PGG, Mulleners WM, Teernstra OPM, Bartels EC, Burger K, Wille F, van Dongen RTM, Kurt E, Spincemaille GH, Haan J, van Zwet EW, Huygen FJPM, Ferrari MD; ICON study group. Safety and efficacy of occipital nerve stimulation for attack prevention in medically intractable chronic cluster headache (ICON): a randomised, 
double-blind, multicentre, phase 3, electrical dose-controlled trial. Lancet Neurol. 2021;20:515-525. Large study on greater occipital nerve stimulation however without sham control; interpreted as a positive study.

35. Mueller OM, Gaul C, Katsarava Z, Diener HC, Sure U, Gasser T. Occipital nerve stimulation for the treatment of chronic cluster headache - lessons learned from 18 months experience. Cent Eur Neurosurg. 2011;72:84-9.

36. Trentman TL, Rosenfeld DM, Vargas BB, Schwedt TJ, Zimmerman RS, Dodick DW. Greater occipital nerve stimulation via the Bion microstimulator: implantation technique and stimulation parameters. Clinical trial: NCT00205894. Pain Physician. 2009;12:621-628.

37. Strand NH, Trentman TL, Vargas BB, Dodick DW. Occipital nerve stimulation with the Bion $®$ microstimulator for the treatment of medically refractory chronic cluster headache. Pain Physician. 2011;14:435-40.

38. Garcia-Ortega R, Edwards T, Moir L, Aziz TZ, Green AL, FitzGerald JJ. Burst Occipital Nerve Stimulation for Chronic Migraine and Chronic Cluster Headache. Neuromodulation. 2019;22:638-44.

39. Goadsby PJ, May A. PET demonstration of hypothalamic activation in cluster headache. Neurology. 1999;52:1522.

40. Sprenger T, Boecker H, Tolle TR, Bussone G, May A, Leone M. Specific hypothalamic activation during a spontaneous cluster headache attack. Neurology. 2004;62:516-7.

41. Akerman S, Holland PR, Summ O, Lasalandra MP, Goadsby PJ. A translational in vivo model of trigeminal autonomic cephalalgias: therapeutic characterization. Brain. 2012;135:3664-75.

42. Schytz HW, Barlose M, Guo S, et al. Experimental activation of the sphenopalatine ganglion provokes cluster-like attacks in humans. Cephalalgia. 2013;33:831-41.

43. Guo S, Petersen AS, Schytz HW, et al. Cranial parasympathetic activation induces autonomic symptoms but no cluster headache attacks. Cephalalgia. 2018;38:1418-28.

44. Barloese MC, Jürgens TP, May A, et al. Cluster headache attack remission with sphenopalatine ganglion stimulation: experiences in chronic cluster headache patients through 24 months. J Headache Pain. 2016;17:67.

45. Jürgens TP, Barloese M, May A, et al. Long-term effectiveness of sphenopalatine ganglion stimulation for cluster headache. Cephalalgia. 2017;37:423-34.

46. Barloese M, Petersen A, Stude P, Jürgens T, Jensen RH, May A. Sphenopalatine ganglion stimulation for cluster headache, results from a large, open-label European registry. J Headache Pain. 2018;19:6.

47. Ansarinia M, Rezai A, Tepper SJ, Steiner CP, Stump J, StantonHicks M, Machado A, Narouze S. Electrical stimulation of sphenopalatine ganglion for acute treatment of cluster headaches. Headache. 2010;50:1164-74.

48.• Goadsby PJ, Sahai-Srivastava S, Kezirian EJ, et al. Safety and efficacy of sphenopalatine ganglion stimulation for chronic cluster headache: a double-blind, randomised controlled trial. Lancet Neurol. 2019;18:1081-1090. Only sham controlled study showing an efficacy of sphenopalatine ganglion stimulation in the acute treatment of chroncic cluster headache.

49. Schoenen J, Jensen RH, Lanteri-Minet M, et al. Stimulation of the sphenopalatine ganglion (SPG) for cluster headache treatment. Pathway $\mathrm{CH}-1$ : a randomized, sham-controlled study. Cephalalgia. 2013;33:816-830.

50. Bendersky DC, Hem SM, Yampolsky CG. Unsuccessful pulsed radiofrequency of the sphenopalatine ganglion in patients with chronic cluster headache and subsequent successful thermocoagulation. Pain Pract. 2015;15:E40-45.

51. Salgado-Lopez L, de Quintana-Schmidt C, Belvis Nieto R, et al. Efficacy of sphenopalatine ganglion radiofrequency in refractory chronic cluster headache. World Neurosurg. 2019;122:e262-9.

52. Holland PR, Akerman S, Goadsby PJ. Cortical spreading depression-associated cerebral blood flow changes induced by mechanical stimulation are modulated by AMPA and GABA receptors. Cephalalgia. 2010;30:519-27.

53. Lipton RB, Dodick DW, Silberstein SD, et al. Single-pulse transcranial magnetic stimulation for acute treatment of migraine with aura: a randomised, double-blind, parallel-group, shamcontrolled trial. Lancet Neurol. 2010;9:373-80.

54. Bhola R, Kinsella E, Giffin N, et al. Single-pulse transcranial magnetic stimulation (sTMS) for the acute treatment of migraine: evaluation of outcome data for the UK post market pilot program. J Headache Pain. 2015;16:535.

55. Misra UK, Kalita J, Bhoi SK. High-rate repetitive transcranial magnetic stimulation in migraine prophylaxis: a randomized, placebo-controlled study. J Neurol. 2013;260:2793-801.

56. Leung A, Shirvalkar P, Chen R, et al. Transcranial magnetic stimulation for pain, headache, and comorbid depression: INSNANS expert consensus panel review and recommendation. Neuromodulation. 2020;23:267-90.

57. Hodaj H, Alibeu JP, Payen JF, Lefaucheur JP. Treatment of chronic facial pain including cluster headache by repetitive transcranial magnetic stimulation of the motor cortex with maintenance sessions: a naturalistic study. Brain Stimul. 2015;8:801-7.

58. Magis D, D’Ostilio K, Lisicki M, Lee C, Schoenen J. Anodal frontal tDCS for chronic cluster headache treatment: a proof-ofconcept trial targeting the anterior cingulate cortex and searching for nociceptive correlates. J Headache Pain. 2018;19:72.

59. Narouze SN, Kapural L. Supraorbital nerve electric stimulation for the treatment of intractable chronic cluster headache: a case report. Headache. 2007;47:1100-2.

60. Mercieri M, Negro A, Silvestri B, D'Alonzo L, Tigano S, Arcioni R, Martelletti P. O065. Drug-resistant chronic cluster headache successfully treated with supraorbital plus occipital nerve stimulation. A rare case report. J Headache Pain. 2015;16(Suppl 1):A97.

61. Wolter T, Kiemen A, Kaube H. High cervical spinal cord stimulation for chronic cluster headache. Cephalalgia. 2011;31:1170-80.

62. Lambru G, Trimboli M, Palmisani S, Smith T, Al-Kaisy A. Safety and efficacy of cervical $10 \mathrm{kHz}$ spinal cord stimulation in chronic refractory primary headaches: a retrospective case series. J Headache Pain. 2016;17:66.

63. Franzini A, Messina G, Leone M, Cecchini AP, Broggi G, Bussone G. Feasibility of simultaneous vagal nerve and deep brain stimulation in chronic cluster headache: case report and considerations. Neurol Sci. 2009;30(Suppl 1):S137-139.

64. Mammis A, Gudesblatt M, Mogilner AY. Peripheral neurostimulation for the treatment of refractory cluster headache, long-term follow-up: case report. Neuromodulation. 2011;14:432-5.

65. Belvis R, Rodríguez R, Guasch M, Álvarez MJ, Molet J, Roig C. Efficacy and safety of surgical treatment of cluster headache. Med Clin. 2020;154:75-9.

Publisher's Note Springer Nature remains neutral with regard to jurisdictional claims in published maps and institutional affiliations. 